\title{
Autophosphorylation of the KaiC-like protein ArlH inhibits oligomerisation and interaction with Arll, the motor ATPase of the archaellum
}

\author{
J. Nuno de Sousa Machado ${ }^{1,2}$, Leonie Vollmar ${ }^{2,3}$, Julia Schimpf ${ }^{2,3}$, Paushali \\ Chaudhury $^{1}$, Rashmi Kumariya ${ }^{1}$, Chris van der Does ${ }^{1}$, Thorsten Hugel ${ }^{3}$ and Sonja- \\ Verena Albers ${ }^{1, *}$
}

\begin{abstract}
${ }^{1}$ Molecular Biology of Archaea and Signaling Research Centre BIOSS, Institute of Biology II, Faculty of Biology, University of Freiburg, Freiburg, Germany

${ }^{2}$ Spemann Graduate School of Biology and Medicine, University of Freiburg, Freiburg, Germany

${ }^{3}$ Institute of Physical Chemistry and Signaling Research Centers BIOSS and CIBSS, University of Freiburg,

Freiburg, Germany
\end{abstract}

${ }^{*}$ Corresponding author: Sonja-Verena Albers, e-mail: sonja.albers@biologie.uni-freiburg.de

\begin{abstract}
Motile archaea are propelled by the archaellum, whose motor complex consists of the membrane protein ArIJ, the ATPase Arll, and the ATP-binding protein ArIH. Despite its essential function and the existence of structural and biochemical data on ArlH, the role of ArlH in archaellum assembly and function remains elusive. ArlH is a structural homolog of KaiC, the central component of the cyanobacterial circadian clock. Similar to KaiC, ArlH exhibits autophosphorylation activity, which was observed for both ArlH of the euryarchaeon Pyrococcus furiosus (PfArlH) and the crenarchaeon Sulfolobus acidocaldarius (SaArlH). Using a combination of single molecule fluorescence measurements and biochemical assays, it is shown that autophosphorylation of ArIH is closely linked to the oligomeric state of ArlH bound to Arll. These experiments also strongly suggest that ArlH is a hexamer in its functional Arll bound state. Mutagenesis of the putative catalytic residue Glu-57 in SaArlH results in a reduced autophosphorylation activity and abolished archaellation and motility, suggesting that optimum phosphorylation activity of ArlH is essential for both archaellation and motility.
\end{abstract}

\section{Introduction}

The ability to escape stressful conditions towards environments where growth is optimal can be found across all domains of life (1). In Archaea, motility can be achieved by passive means, e.g., gas vesicles for floating (2), or by active propulsion through liquid media powered by archaella (3). Archaella are functionally analogous to the bacterial flagellum, but these two nanomachines are structurally distinct and evolved independently $(1,3-5)$. The archaellum is evolutionarily related to type IV pili (T4P) of bacteria and archaea and to type II secretion systems (T2SS) (6) and shares some biochemical properties with these machineries, e.g., its assembly and rotation is ATP-driven and the pilin and archaellin precursors are processed in a similar manner (7-9). The functional similarities between the flagellum and the archaellum and the repurposing of a T4P with a rotary motor are extraordinary examples of convergent and divergent evolution (3).

The archaellum is a relatively simple motility structure, with the archaellum from the model organism Sulfolobus acidocaldarius requiring only seven different structural proteins for its function and a membrane-embedded signal peptidase to cleave the signal peptide of pre-archaellinds (See Fig. 1) (10). These proteins are encoded in the arl (archaellin-related genes) cluster, which was previously named the fla cluster (11). The arl cluster encodes the structural unit (ArIB, archaellin) of the filament and the $\mathrm{ArIX} / \mathrm{G} / \mathrm{F} / \mathrm{H} / \mathrm{I} / \mathrm{J}$ proteins which constitute the archaellum assembly and rotary machinery (See Fig. 1) (4). ArlX is found exclusively in Crenarchaeotes and its function was proposed to be replaced in Euryarchaeotes by the ArIC/D/E proteins (Fig. 1) $(3,12)$. It was proposed that this is an adaptation to the bacterial-like chemotaxis system 
present in Euryarchaeotes (13-16). In Haloferax volcanii, ArIC/D/E localise to the cell poles in an ArlHdependent manner, where they are the direct receivers of chemotactic signals transduced by $\mathrm{CheF}$ $(17,18)$. These cytosolic proteins have further been hypothesized to interact with the polar cap that is present in Euryarchaea (See Fig. 1) (18-21).

As with any rotary motor, the archaellum motor requires both a rotor and a stator. It has been hypothesised that ArIX, ArIG, and ArIF are part of the crenarchaeal stator (22-24), whereas ArlH, Arll, and ArlJ form the rotor. ArIG and ArIF form a complex at the tip of a filament formed by ArIG. ArIG is anchored in the membrane and ArIF binds to the S-layer proteins, thus anchoring the archaellum to the Slayer (24). ArIX contains a N-terminal transmembrane domain followed by a cytosolic domain. ArIX from S. acidocaldarius (SaArIX) forms high molecular weight complexes that adopt a ringlike structure large enough to enclose the $\mathrm{ArlH} / \mathrm{I} / \mathrm{J}$ motor complex $(22,25)$.

Arll is a hexameric ATPase. Conformational variation in the hexamer of $S$. acidocaldarius Arll (SaArll) provides a model for how successive rounds of ATP binding, hydrolysis and product release result in conformational changes that drive both archaellum assembly and rotation (27). Deletion of the first 29 residues of SaArll abolished motility but not archaella assembly, demonstrating that these two processes can be separated (27). The polytopic membrane protein ArlJ, homologous to the platform protein present in T4P (e.g. PilC of Myxococcus xanthus), is not only conserved across motile archaea but also essential for archaella assembly $(10,28-31)$. The structure of ArlJ is unknown, but bioinformatical predictions suggest the presence of positively charged cytosolic loops that may mediate its interaction with Arll. ArlJ might then transfer the ATPdependent conformational movements of Arll across the cell membrane $(27,29)$. The structures of SaArlH and ArlH from Methanocaldococcus jannaschii $(\mathrm{MjArlH})$ have been determined $(26,32)$. Both proteins crystallised as monomers, but structural modelling based on homologous proteins of known structure suggests that $\mathrm{ArlH}$ can also form higher oligomeric species. Indeed, cross-linking experiments showing that PfArlH has the potential to form hexamers in vitro $(26,32)$. SaArlH, MjArlH and PfArlH bind ATP but none of them showed ATPase activity in standard ATPase assays $(26,32)$. ArlH possesses the canonical Walker $A(W A)$ as well as a Walker B (WB) motif which is typical of RecA family proteins, where a threonine or serine residue follows the conserved aspartate instead of the carboxylate seen in AAA+ ATPases (26, 32-34).

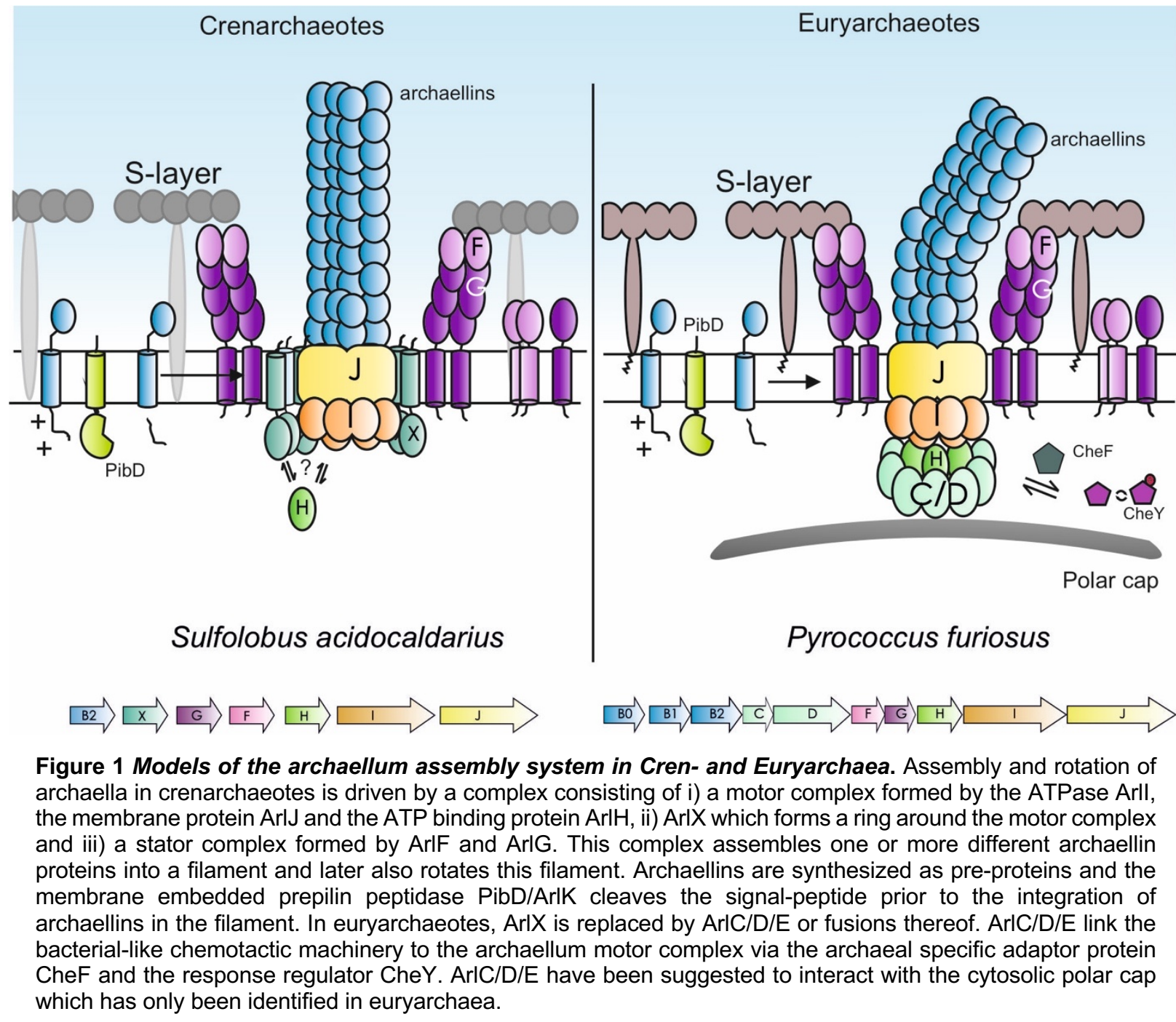


SaArlH, SaArll and SaArlX have been shown to interact with each other with high affinity (25) and SaArlH was imaged by cryo-EM showing 8-10 monomers inside the SaArIX ring (26). A composite model of the archaellum machinery of $P$. furiosus shows a bell-shaped cytosolic complex of Arll and ArlH and a surrounding cytosolic ring, most likely consisting of ArIC/D/E (20). Several studies have addressed the interaction between $\mathrm{ArlH}$ and Arll. Mutations in the Walker A and B motifs of SaArlH are not only critical for ATP binding but also abolish the interaction between SaArll and SaArlH. Similar mutations in PfArlH abolish the observed stimulation of the ATPase activity of PfArll by PfArlH. Accordingly, $S$. acidocaldarius cells carrying genomic arlHWA and WB mutations were unable to assemble archaella, indicating a key regulatory function in archaellum assembly and motility for ArlH (26). Furthermore, purified SaArlH and PfArlH retain significant amounts of bound nucleotide and removal of the nucleotide by ammonium sulphate precipitation or introduction of mutations that negatively interfere with ATP binding destabilize these proteins. These data together demonstrate the importance of nucleotide binding to $\mathrm{ArlH}$ and its interaction with Arll. Of note, the interaction between MjArlH and MjArll became weaker with increasing ATP concentration (32).

Both crystal structures of ArlH showed a typical RecA/RAD51 fold with a large, central $\beta$-sheet surrounded by $\alpha$-helices. Interestingly, the closest structural homologue of $\mathrm{ArlH}$ is KaiC, the central protein in the regulation of the cyanobacterial circadian rhythm $(26,32,35)$. KaiC has two domains (KaiCl and KaiClI) which assemble into a hexameric dumbbell-shaped complex (36). The N-terminal domain, formed by $\mathrm{KaiCl}$, has been associated with hexamerisation of the complex (37), whereas the Cterminus formed by the KaiCll domain shows sequential autophosphorylation and autodephosphorylation at $\mathrm{S} 431$ and T432. This sequential phosphorylation and dephosphorylation regulates the periodicity of the cyanobacterial circadian cycle $(35,36,38-43)$.

Given the homology between $\mathrm{KaiC}$ and $\mathrm{ArlH}$, we set out to further explore the biochemical properties of ArlH and compare them with KaiC. In this study, we show that $\mathrm{ArlH}$ is structurally homologous to the KaiCll domain of KaiC and that ArlH undergoes autophosphorylation. In addition, we show that ArlH hexamerises in the presence of Arll and that this interaction depends on the phosphorylation status of ArlH. Altogether, this allows us to propose a mechanism on how ArlH modulates Arll via a phosphorylation-dependent mechanism.

\section{Results}

\section{ArlH is a KaiC-like protein with autophos- phorylation activity}

Previous studies have shown that $\mathrm{ArlH}$ is homologous to KaiC, the central component of the circadian rhythm clock of cyanobacteria $(26,32,39)$. Since KaiC has two ATPase domains (KaiCl, involved in hexamerisation and KaiCll, involved on autophosphorylation (39-41)), while ArlH consists of

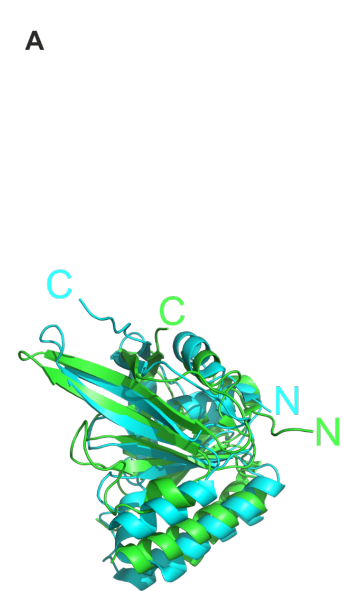

$\mathrm{KaiCl}$ and SaArlH $\mathrm{RMSD}=4.195 \AA$

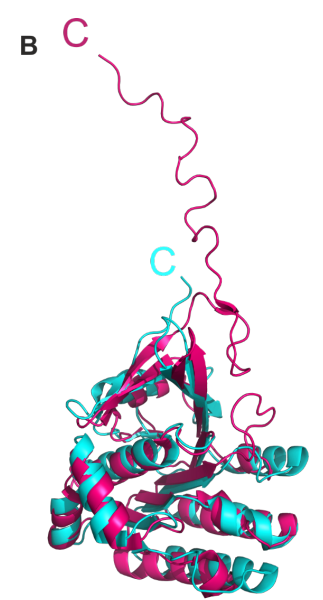

KaiCll and SaArlH $\mathrm{RMSD}=2.402 \AA$
Figure $2 \mathrm{SaArIH}$ is structurally more similar to the KaiCll domain than to KaiCl domain of KaiC. Structural alignment of (A) SaArlH (in cyan; PDB: 4YDS) and KaiCl (in green; residues 16-246; PDB: 4TL8) or (B) SaArlH and KaiCll (in pink; residues 262-519; PDB: 2GBL). For both alignments, solvent molecules, ions, and other ligands were removed prior to structural alignment. The alignment was performed on PyMol with the command "align", and outlier atoms were removed.

identified in eurvarchaea.

a single ATP-binding domain, the structure of SaArlH was aligned with the Synechococcus elongatus KaiCl and KaiCll domains, as defined by Pattanayek et al., 2004 (36). This structural alignment showed a higher similarity of SaArlH with KaiCll (rmsd $2.402 \AA$, 754 atoms) than with $\mathrm{KaiCl}$ (rmsd 4.195 $\AA, 1029$ atoms) (Fig. 2). A similar observation was made when $\mathrm{MjArlH}$ was aligned to the KaiCl and KaiCll domains (Supplementary Fig. 1). Since ArlH shows more similarity to the KaiCll domain, this suggested that ArlH might have autophosphorylation activity.

The hyperthermophile $S$. acidocaldarius has been an important model organism for studies on archaeal motility. When heterologously expressed SaArlH was purified and incubated with $\mathrm{y}^{32}{ }^{32} \mathrm{P}-\mathrm{ATP}$ in the presence of $\mathrm{Mg}^{2+}$ at $55^{\circ} \mathrm{C}$ for 1 hour, a timedependent increase in signal was observed at the height of SaArlH after separation on acrylamide gels (Fig. 3 and Supplementary Fig. 2). No signal was observed when similar assays were performed with SaArlH and $\alpha^{-}{ }^{32} \mathrm{P}-\mathrm{ATP}$, demonstrating that the signal is derived from the transferred $\mathrm{Y}$-phosphate. To exclude that the observed signal is derived from a hypothetical contaminating $E$. coli promiscuous protein kinase, a similar phosphorylation assay was performed with $\mathrm{SaArlH}$ variants which were mutated in the Walker $A\left(S a A r l H^{\mathrm{K} 33 \mathrm{~A}}\right)$ or the Walker $B$ $\left(\right.$ SaArlH ${ }^{\mathrm{D} 122 \mathrm{~N}}$ ) motifs (Supplementary Fig. 2). Both mutations result in strongly reduced ATP binding (26) and no phosphorylation signal was observed (Fig. 3). Together these data show that SaArlH undergoes slow time-dependent autophosphorylation in vitro. In order to test whether autophosphorylation is a universal property of $\mathrm{ArlH}$ proteins, it was tested whether an ArlH from an Euryarchaeal hyperthermophile can also autophosphorylate. Wild- 


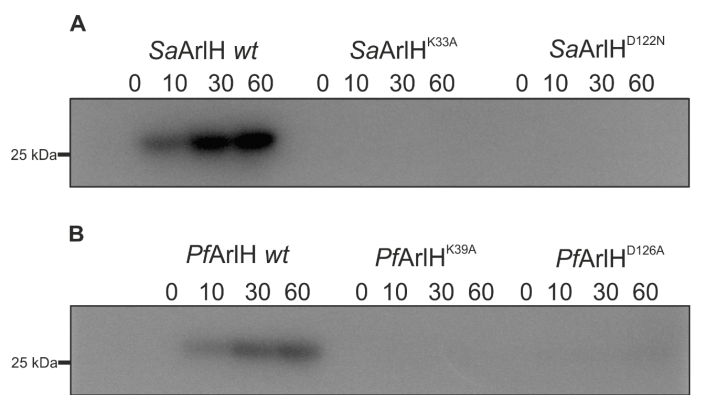

Figure 3 ArlH shows autophosphorylation activity. (A) WT SaArlH and SaArlH proteins containing mutations in the walker $A(K 33 A)$ and walker $B(D 122 N)$ motifs were incubated with $\mathrm{y}^{-}{ }^{32} \mathrm{P}$ ATP for different times at $55^{\circ} \mathrm{C}$, separated on SDSPAGE and analysed by phospho-imaging. (B) Similar experiments were performed at $65^{\circ} \mathrm{C}$ with WT PfArlH and PfArlH proteins containing mutations in the walker $A$ (K39A) and walker $B$ (D126A) motifs. The molecular size marker is shown.

type PfArlH and PfArlH with mutations in the WA $\left(P f A r l H^{\mathrm{K} 39 \mathrm{~A}}\right)$ and WB (PfArlH $\left.{ }^{\mathrm{D} 126 \mathrm{~A}}\right)$ motifs were also purified (Supplementary Fig. 2) and tested in autophosphorylation assays. Similar results to those obtained for SaArlH were obtained for PfArlH (Fig. 3), suggesting that autophosphorylation activity is a conserved feature of $\mathrm{ArlH}$.

\section{ArIH oligomerises in the presence of Arll}

Although a model of a hexameric ArlH has been proposed, experimental evidence for the oligomeric state of this protein in the presence of other archaellum motor proteins is lacking $(26,32)$. To study the oligomerization of $\mathrm{ArlH}$ in the presence of Arll, single molecule total internal reflection fluorescence (smTIRF) microscopy was used to explore different conditions under which $\mathrm{ArlH}$ might form oligomers. Similar studies have been performed to count the subunits in other systems like, e.g., FliM from flagella and pRNA from the phi29 DNApackaging motor (44-48). The experiments were performed with single cysteine mutants of PfArlH $\left(P f A r l H^{\mathrm{S} 109 \mathrm{C}}\right)$ and PfArll since these proteins were more stable and higher labelling efficiencies could be obtained than with different SaArlH and SaArll cysteine mutants. The size of the ArlH oligomers was determined by two colour single molecule fluorescence bleaching step assays in the presence of PfArll. First, biotinylated PfArll was immobilized in a microfluidic chamber (Fig. 4A); then, fluorescently labelled PfArlH was fed into the microfluidic chamber, resulting in immobilisation of PfArlH via PfArll on the surface. Since less bleaching steps (e.g., three instead of six) are easier to detect in a single fluorescence bleaching trace, labelling of PfArlH was performed with two different dyes, Atto550 and Atto647N. The chamber was alternatingly illuminated with a green (for Atto550) and a red (for Atto647N) laser light and the bleaching steps in each colour were determined (Fig. 4B). The summed-up bleaching steps per oligomer were then corrected for the degree of labelling (see methods for details). The results from six different repetitions on six different days with six different sample batches are shown in Fig. 5A for PfArlH (yellow). Several different oligomer sizes can be observed, including a significant number of hexamers (about 12\%) and trimers (about 37\%). This shows that $\mathrm{ArlH}$ oligomerises in the presence of Arll.

\section{ArlH autophosphorylation reduces the oligomer size of ArlH in presence of Arll}

To test the effect of ATP on the oligomerization of PfArlH, the smTIRF bleaching experiment was repeated in the presence of ATP under two different conditions. First, to test for the effect of ATP binding, i.e., in the non-phosphorylating conditions, PfArlH was incubated with ATP in the presence of $\mathrm{Mg}^{2+}$ at room temperature (RT) for 1 hour. Since PfArlH is derived from a thermophilic organism, at RT, PfArlH binds ATP with high affinity (Supplementary Fig. 5) but the phosphorylation activity is very low. Second, to test for the effect of ATP hydrolysis, i.e., under phosphorylating conditions, PfArlH was incubated with ATP in presence of $\mathrm{Mg}^{2+}$ at $65^{\circ} \mathrm{C}$ for one hour. Under non-phosphorylating conditions a clear shift to higher oligomeric species was observed when compared to the absence of ATP, with the two populations differing significantly with a shift to higher oligomeric species under non-phosphorylating
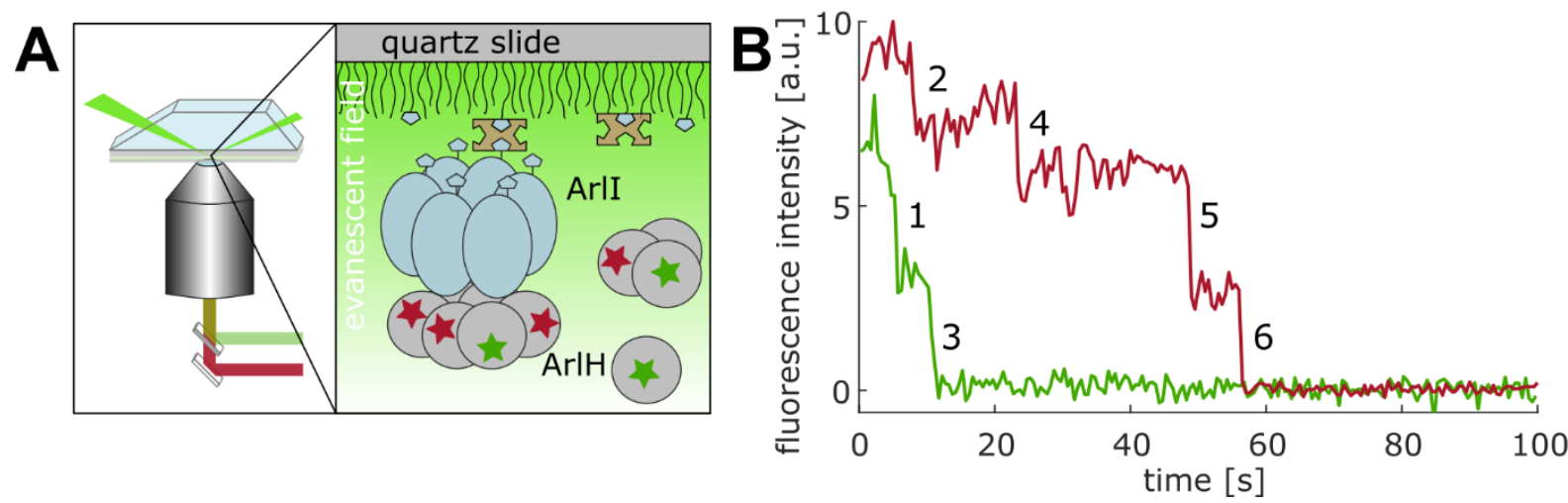

Figure 4 Single-molecule TIRF measurements were performed to assess the oligomeric state of ArIH. A) Schematics of the two colour single molecule TIRF experiment. Biotinylated Arll is immobilized on the PEGylated quartz slide via biotin-NeutrAvidin binding. Oligomers of labelled ArlH bind to Arll. B) Example trace with a total of six bleaching steps. 

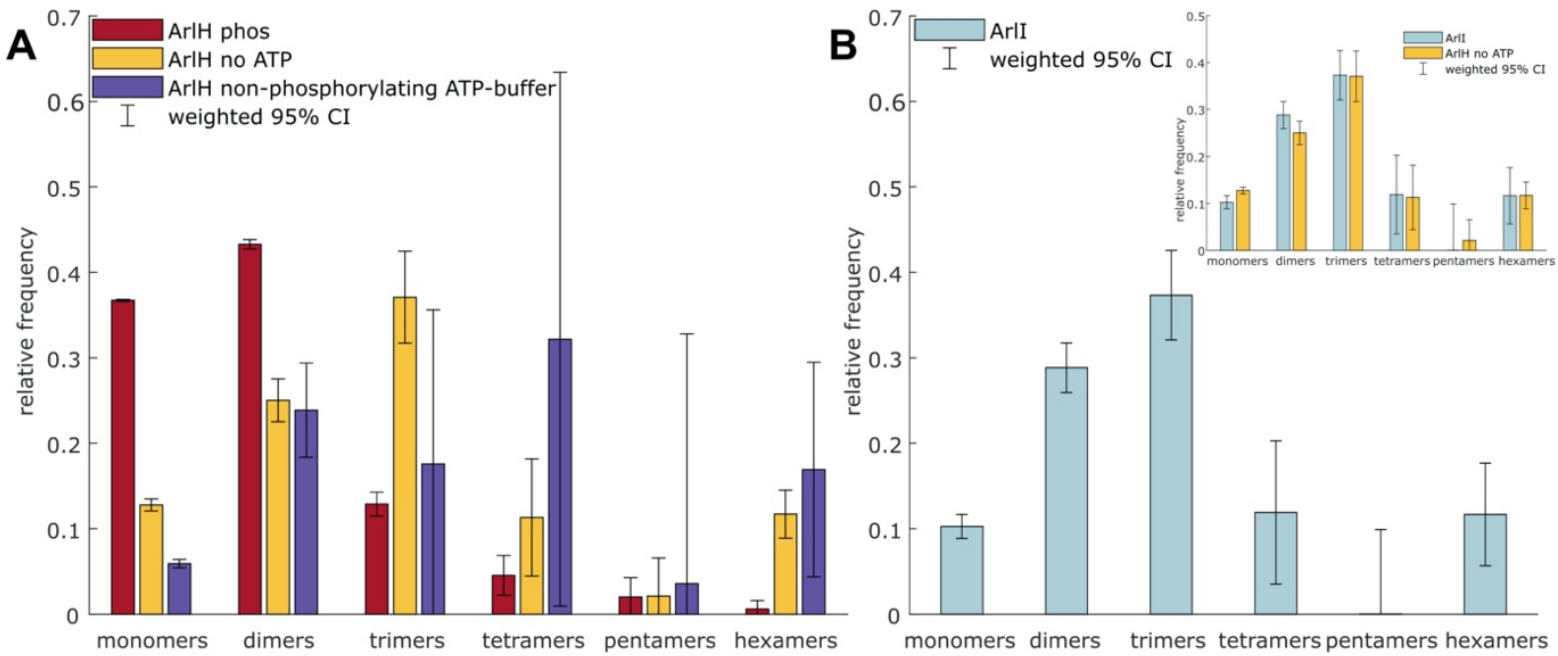

Figure 5 ArlH interacts with Arll as a hexamer and shifts to lower oligomeric forms when phosphorylated. A) Comparison of the measured oligomer size for PfArlH without ATP (yellow), phosphorylated PfArlH (red) and with ATP under non-phosphorylating conditions (violet), showing that ATP binding is not sufficient to regulate PfArlH's oligomerization. B) TIRF bleaching experiments with labelled, biotinylated PfArll (20 pM) confirm that PfArll forms oligomers. In the inset, the bleaching experiments performed on PfArll are directly compared with the bleaching experiments performed for PfArlH without ATP, revealing that the distributions are very similar.

conditions (t-test $(\mathrm{t}(6242)=14.6559, \mathrm{p}<<0.001,6242$ $=$ degrees of freedom $=$ sum of oligomers of the two conditions compared here) (Fig. 5A, violet).

In the second case, when ArlH was phosphorylated, the oligomer size clearly decreased to mainly monomers and dimers (altogether 80\%) (Fig.5A red). This result is confirmed by a t-test $(\mathrm{t}(5576)=-29.3370, \mathrm{p}<<0.001,5576=$ degrees of freedom $=$ sum of oligomers of the two conditions compared here). Thus, phosphorylated ArlH forms the smallest oligomeric species (mainly monomers and dimers) in the presence of PfArll, while nonphosphorylated $\mathrm{ArlH}$ already shows larger oligomeric species (more than 50\% oligomers larger than dimers), which is further increased if in the presence of excess ATP (but with non-phosphorylated protein).

\section{PfArlH interacts with PfArll in a 1:1 stoichiometry}

Previous data has provided overwhelming evidence that Arll forms hexamers $(20,27,32,49)$. Moreover, the homologous ATPases PilT and PilB of T4P systems have also been shown to form hexamers (50). Fig. 5B shows the result of two independent TIRF bleaching experiments with labelled PfArll $290 \mathrm{~S} / \mathrm{T} 411 \mathrm{C}$. Hexamers can clearly be observed, but also many trimers and dimers. In fact, the oligomer size distribution looks remarkably like that of PfArlH interacting with PfArll (Fig. 5B, inset). The populations of unphosphorylated $P f A r l H$ and PfArll show no significant difference (t-test: $p=0.7141$ $\mathrm{t}$-value $(4092)=0.3663)$. This strongly hints towards a $1: 1$ binding stoichiometry between PfArlH and PfArll. Therefore, our smTIRF data suggests that ArlH exists as a hexamer at least in one, most likely the functional, form when it interacts with Arll.

Phosphorylation inhibits the interaction between SaArll and SaArlH
To test whether phosphorylation also modifies the $\mathrm{SaArlH} / \mathrm{SaArll}$ interaction, SaArlH was incubated for 3 hours at $55^{\circ} \mathrm{C}$ with ATP to allow for autophosphorylation. Then the interaction between Arll and $\mathrm{ArlH}$ was tested using bio-layer interferometry. While non-phosphorylated SaArlH binds SaArll with a $K_{D}$ of $638 \pm 161 \mathrm{nM}$, their interaction is severely reduced when SaArlH is incubated under phosphorylating conditions prior to the binding assay (Fig. 6). This strongly supports that the phosphorylation status of $\mathrm{ArlH}$ universally modulates its interaction with Arll.

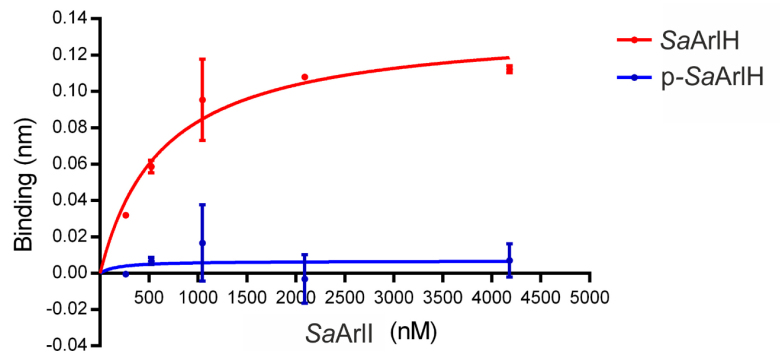

Figure 6 The interaction between SaArIH and SaArll is strongly reduced when SaArlH is phosphorylated. Bio-layer interferometry assays with SaArlH and SaArll were performed. Histagged SaArlH or His-tagged SaArlH preincubated with ATP at $55^{\circ} \mathrm{C}(\mathrm{p}-\mathrm{SaArlH})$ were bound to the surface and incubated with different amounts of SaArll. SaArll interacted with surface bound SaArlH with a $\mathrm{K}_{\mathrm{D}}$ of $638 \pm 16 \mathrm{nM}$. When SaArlH was pre-incubated with ATP, thus resulting in phosphorylated SaArlH, SaArll bound SaArlH with a much lower affinity. 


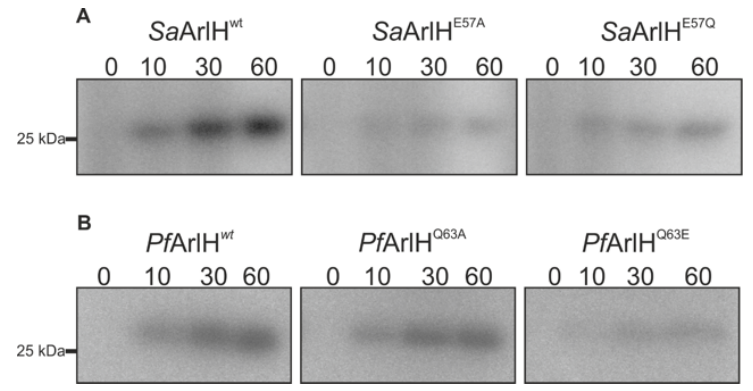

Figure 7 The autophosphorylation activity of ArlH is reduced when the catalytic residue is mutated to an amino acid of opposite charge. The catalytic glutamate of KaiCll is conserved in $\mathrm{ArlH}$, with the exception of Euryarchaeota which seem to have instead an invariable glutamine at this position. (A) WT SaArlH and SaArlH proteins containing mutations in the catalytic glutamate (E57A and E57Q) were incubated with $\mathrm{y}^{-32} \mathrm{P}$-ATP for different times at $55^{\circ} \mathrm{C}$, separated on SDSPAGE and analysed by phospho-imaging. (B) Similar experiments were performed at $65^{\circ} \mathrm{C}$ with WT PfArlH and PfArlH proteins containing mutations in the corresponding glutamine (Q63A and Q63E).

\section{Identification of phosphorylation sites in ArlH}

Since phosphorylation of $\mathrm{ArlH}$ might be an important mechanism in the function of the archaellum, identifying the phosphorylated residues was particularly important. Unfortunately, despite extensive efforts, it was not possible to determine the putative phosphorylation sites of ArlH using mass spectrometry. Therefore, different residues which could be involved in phosphorylation were mutated and the resulting protein variant characterised. The SaArlH T171 and S172 residues, which are located in the same region of the alignment as $S$. elongatus KaiC S431 and T432 (Supplementary Fig. 3), were mutated to alanine. Autophosphorylation assays with the double mutant SaArlH ${ }^{\text {T171ANS172A }}$ showed that phosphorylation was identical to that of the wild-type SaArlH (Supplementary Fig. 4), demonstrating that these residues do not play a role as phosphorylation sites. Structural alignment of ArlH with the KaiCII domain suggested another Ser/Thr pair (T55 and T56 in SaArlH) located in the vicinity of the ATP-binding pocket of ArlH. This pair is highly conserved across ArlH proteins, although not in Kaic. These residues were mutated to the structurally related valine amino acid and the purified proteins (Supplementary Fig. 2) analysed for autophosphorylation. While the mutant SaArlH ${ }^{\mathrm{T} 55 \mathrm{~V}}$ shows the same phosphorylation as wildtype SaArlH, phosphorylation was abolished in SaArlH ${ }^{T 56 V}$ (Supplementary Fig. 4). A MANT-ATP binding assay was performed with both mutants to check whether they were still able to bind ATP. While SaArlH $H^{T 55 V}$ still bound ATP, SaArlH ${ }^{\top 56 \mathrm{~V}}$ was unable to bind ATP (Supplementary Fig. 5). This explains the absence of phosphorylation in SaArlH ${ }^{\mathrm{T} 56 \mathrm{~V}}$, but neither supports nor refutes T56 as a potential phosphorylation site. Similar residues in PfArlH (S61 and S62) were mutated to the structurally similar cysteine residue, and these variants were purified
(Supplementary Fig. 2). In these cases, all three variants - wild-type and single mutants for each residue - showed similar autophosphorylation patterns (Supplementary Fig. 4) and similar ATPbinding affinities (Supplementary Fig. 6), suggesting that at least in PfArlH these residues are not involved in phosphorylation.

\section{The conserved catalytic glutamate is important for ArlH autophosphorylation and essential for motility}

Since no further clear candidates for the phosphorylation site in ArlH could be identified by bioinformatics, the conserved E57 was mutated. This residue is conserved across ArlH proteins, except for several Euryarchaeota, where the residue at this position is a glutamine instead of a glutamate. This residue aligns with two conserved glutamate residues (E318 and E319 in S. elongatus) which have been proposed to play an important role in phosphorylation, with E318 functioning as the general base $(33,36-38,41,51)$. Mutations in this residue in KaiC either abolish or reduce its autophosphorylation activity $(37,38,52)$. This residue was mutated in both $\mathrm{SaArlH}$ and $P$ fArlH. SaArlH ${ }^{E 57 A}$, SaArlH ${ }^{E 57 Q}$ (Fig. 7A) and PfArlH ${ }^{\text {Q63E }}$ (Fig. 7B) showed lower autophosphorylation activity than the wild-type protein, whereas $P f A_{1 H} H^{Q 63 A}$ showed wild-type levels of phosphorylation (Fig. 7B). It is difficult to test motility of $P$. furiosus as it is a hyperthermophilic anaerobic organism, but genomic SaarlH $H^{E 57 A}$ and SaarlH ${ }^{E 57 Q}$ single mutants were created and tested for both archaellation and motility on semi-gelrite plates at $75^{\circ} \mathrm{C}$ (Fig. 8). Strikingly, neither mutant is archaellated nor motile (Fig. 8),

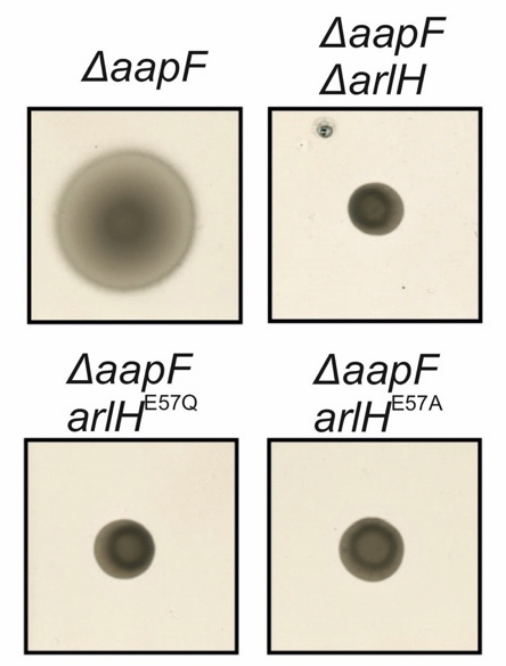

Figure 8 Optimal phosphorylation levels are essential for motility.

The motility of $S$. acidocaldarius strains carrying the indicated genomic mutations was determined. Same amounts of cells were spotted on semi-solid gelrite plates. After incubating at $75^{\circ} \mathrm{C}$ for 5 days, the plates were scanned and recorded. $\triangle a a p F$ and $\triangle$ aapF $\triangle$ arl $H$ were used as hyper-motile and nonmotile control, respectively. The figures shown here were representative examples of biological triplicates. 
bioRxiv preprint doi: https://doi.org/10.1101/2021.03.19.436134; this version posted March 19, 2021. The copyright holder for this preprint (which was not certified by peer review) is the author/funder, who has granted bioRxiv a license to display the preprint in perpetuity. It is made available under aCC-BY-NC 4.0 International license.

suggesting that optimum phosphorylation is essential for archaellation.

\section{Discussion}

KaiC-like proteins have been identified in Archaea, where they were recognised as part of the superfamily that includes DnaB from bacteria, Rad51/DMC1 from eukaryotes, and RadA from archaea $(33,53)$. KaiC proteins were first identified in cyanobacteria (54). In these organisms, the rhythmic phosphorylation and dephosphorylation of KaiC regulates global gene expression in a circadian manner, allowing the cells to anticipate periods of light and dark and adapt their metabolism, e.g., photosynthesis and nitrogen fixation, accordingly (35). KaiC-like proteins in other organisms have been assumed to function in similar processes. However, bioinformatic analyses have proposed that KaiC-like proteins in archaea underwent several instances of functionalisation and might be involved in signal transduction $(53,55)$. Indeed, there already is evidence for the functional versatility of KaiC proteins. For example, a KaiC homologue from Legionella pneumophila contributes to oxidative and ionic stress resistance (56), but does not function as a clock and does not interact with an also present KaiB homologue (56). In archaea, KaiC-like proteins have been proposed to interact with putative output domains, of which the ArlH-Arll interaction is an example (55).

$\mathrm{ArlH}$ is a single-domain KaiC-like protein. A previous analysis based on sequence alignment suggested archaeal KaiC-like proteins to be more similar to the $\mathrm{KaiCl}$ domain (57). Here, however, structural alignments with $\mathrm{MjArlH}$ and $\mathrm{SaArlH}$ structures reveal a higher similarity with KaiCll. Indeed, autophosphorylation takes place in the KaiCII domain and this and previous studies $(56,58$, 59) have shown that KaiC-like proteins can autophosphorylate, suggesting that autophosphorylation is a property of KaiC-like proteins independent of their specific function. In this study, a relatively low level of phosphorylation was observed in the autoradiography assays. This might be caused by i) some ArlH being purified in a nucleotide-bound state and a slow release rate for the nucleotide ii) lack of a component that stimulates the phosphorylation rate or iii) $\mathrm{ArlH}$ being both an auto-kinase and an autophosphatase, with these antagonistic activities resulting in a dynamic equilibrium between phosphorylated and nonphosphorylated ArlH.

Previous studies on cyanobacterial KaiC and members of the RecA family demonstrated that ATP hydrolysis by proteins with a RecA-like fold requires residues from adjacent RecA-like domains and that hexamerisation is a common theme in this group of proteins $(60,61)$. This was also suggested for the KaiC-like proteins $\mathrm{PH} 0186$ and $\mathrm{PH} 0284$ from Pyrococcus horikoshii OT3, while another KaiC-like protein from the same organism forms tetramers (62$64)$. ArlH was suggested to fulfil its function in the archaellum motor as a hexamer and a model based on this hypothesis was proposed (26). Previous evidence for different oligomeric forms of $\mathrm{ArlH}$ had been obtained (26) and the data presented in this study further confirms and proposes that $\mathrm{ArlH}$ interacts with Arll as a hexamer. Using smTIRF bleaching experiments, PfArH is shown to exist as higher oligomeric species in the presence of PfArll. The frequency distribution of bleaching steps for $P f A r l H$ is very similar to the frequency distribution of bleaching steps for PfArll, a protein that has been extensively shown to form hexamers $(27,49,65)$. This and data suggests that PfArlH and PfArll interact in a $1: 1$ stoichiometry and, therefore, that PfArlH forms hexamers (65).

ArlH has previously been show to form monomers in solution, although cross-linking experiments suggest as well that ArlH has the potential to form hexamers $(26,32)$. The Arll requirement for stable oligomerisation bears similarities with other RecA proteins which have been reported to require additional domains for a stable hexamerisation (61). Hexamerisation of $\mathrm{KaiC}$ is mainly driven by the $\mathrm{KaiCl}$ domain, with the KaiCll having only a stabilising effect on the hexamer (38). The observation of lowerorder oligomers in these experiments is likely due to the low protein concentrations (pM range) to which the proteins are diluted shortly before the singlemolecule experiments. These concentrations might be around or slightly below the $\mathrm{K}_{\mathrm{D}}$ for the monomers' interaction for both ArlH and Arll.

Once the Arll-dependent oligomerisation of PfArlH had been established, the impact of SaArlH phosphorylation on the SaArlH-SaArll interaction was assessed. Biolayer interferometry measurements showed that when SaArlH is phosphorylated, the interaction between SaArll and SaArlH is strongly reduced (Fig. 6). smTIRF experiments in the presence of PfArll revealed that when PfArlH is phosphorylated there is a shift to lower oligomeric species when compared to non-phosphorylated PfArlH. Such a shift was not observed when assays were performed in the presence of ATP under nonphosphorylating conditions, demonstrating that phosphorylation -not nucleotide binding - is responsible for this change in the oligomeric state. Phosphorylation thus seems to be a conserved feature that modulates the interaction between $\mathrm{ArlH}$ and Arll.

Several attempts at characterising which residues are phosphorylated in this protein failed, as no phospho-peptides could be detected by massspectrometry for either SaArlH or PfArlH. It was however possible to identify a residue - E57 in $S$. acidocaldarius - which results in reduced autophosphorylation activity when mutated to either an alanine or a glutamine residue. Intriguingly, the homologous residue in $P$. furiosus is a glutamine instead of a glutamate - a trend that seems to be common in Euryarchaea apart from halophiles. Mutating the glutamine residue to an alanine does not interfere with the autophosphorylation of PfArlH but changing this residue to a glutamate results in lower phosphorylation activity. Insertion of these mutations in $S$. acidocaldarius cells completely abolished archaella synthesis and, consequently, motility. These results strongly imply that optimum phosphorylation activity of $\mathrm{ArlH}$ is a strict requirement for archaella assembly/maintenance. Moreover, the data suggests that despite their presumably similar functions there are mechanistic differences between ArlHs of cren- and euryarchaeotes. 
bioRxiv preprint doi: https://doi.org/10.1101/2021.03.19.436134; this version posted March 19, 2021. The copyright holder for this preprint (which was not certified by peer review) is the author/funder, who has granted bioRxiv a license to display the preprint in perpetuity. It is made available under aCC-BY-NC 4.0 International license.

Together with the results from previous studies $(26,65)$ we can now describe the interaction between ArlH and Arll in more detail, namely: i) ATP binding to $\mathrm{ArlH}$ is a requirement for the interaction with Arll; ii) ArlH interacts with Arll as a hexamer; iii) hexamerisation of $\mathrm{ArlH}$ is Arll-dependent and iv) phosphorylation of ArlH modulates the ArlH-Arll interaction. Thus, both the nucleotide dependent ArlH-Arll interaction and modulation of this interaction by phosphorylation of $\mathrm{ArlH}$ is likely required in early stages of archaella assembly. This is further supported by the absence of archaella filaments when cells express ArlH mutated in the Walker motifs or with mutations in the E57 residue, which reduce autophosphorylation. To understand how the interaction between ArlH and Arll and its modulation by phosphorylation of ArlH exactly drives the assembly and, at later stages, the rotation of the archaellum must be studied in the presence of other components of the archaellar motor like ArIJ and ArIX (or ArIC/D/E), as these proteins interact with and/or modulate ArlH and Arll.

\section{Experimental procedures}

\section{Strains and Plasmids}

Strains, plasmids and primers used in this study can be found in Tables 1, 2 and 3 respectively, in the Supporting Information. E. coli TOP10 (Invitrogen) was used for cloning and plasmid amplification and $E$. coli Rosetta cells were used for heterologous expression. The NEB ER1821 E. coli strain was used to methylate plasmids for transformation into $S$. acidocaldarius. Heterologous overexpression of proteins in E.coli took place from pETDuet1 derived plasmids with the gene of interest cloned in the multiple cloning site. Insertion of tags was performed by in vivo DNA assembly (66). Site-directed mutagenesis was performed by round PCR using the indicated primers. Insertion of the AviTag (GLNDIFEAQKIEWHE) upstream of arll in pSVA3116 was performed via an intermediate plasmid containing half of the tag, followed by insertion of the remaining fragment using the two indicated primer pairs. All plasmid sequences were confirmed by sequencing.

In vivo point mutations in $S$. acidocaldarius were generated following the protocol described by Lassak et. al (10) with a modification. Shortly, the arlH gene was amplified by PCR from the genomic DNA of S. acidocaldarius DSM639, including $700 \mathrm{bp}$ up- and downstream regions. The primers used for amplification were $3614 / 3617$. The fragment was cloned as an Apal/Pstl digested fragment into the pSVA406 vector, yielding plasmid pSVA2126. Site directed mutagenesis was performed by round PCR using the plasmid pSVA2126 as template, with the primers indicated in Table $\mathbf{3}$ and yielding the plasmids in Table 2 (Supporting information). The plasmids were methylated in E. coli strain ER1821 and transformed into the MW455 $\mathrm{S}$. acidocaldarius strain. This strain is a deletion mutant of $\mathrm{arlH}$ and insertion of the mutated plasmids resulted in knockin of the $\mathrm{arlH}$ variants by homologous recombination to its original locus in the genome.

\section{Cell growth}

Sulfolobus acidocaldarius DSM639 was grown aerobically at $75^{\circ} \mathrm{C}$ in Brock basal medium (67) supplemented with $0.1 \%(\mathrm{w} / \mathrm{v})$ tryptone (Roth) or NZAmine AS (Sigma) and $0.2 \%(\mathrm{w} / \mathrm{v})$ dextrin with $\mathrm{pH}$ adjusted to 3.5 with sulfuric acid. All the uracil auxotrophic stains of $\mathrm{ArlH}$ point mutations, hyperarchaellated wildtype MW156 (S. acidocaldarius $\triangle a a p F$ ), non-archaellated MW455 ( $\triangle a r l H$ in S. acidocaldarius $\triangle a a p F$ background) and the point mutant strains (MW480 and MW490 for the mutations $a r l H^{\mathrm{E} 57 \mathrm{Q}}$ and $a r l H^{\mathrm{E57A}}$, respectively, in the S. acidocaldarius $\triangle a a p F$ background) (10) were grown in Brock medium supplemented with $10 \mu \mathrm{g} / \mathrm{ml}$ uracil. To prepare solid medium for $S$. acidocaldarius, Brock medium was solidified with a final concentration of $0.6 \%(w / v)$ Gelrite (Sigma), $10 \mathrm{mM}$ $\mathrm{MgCl}_{2}$ and $3 \mathrm{mM} \mathrm{CaCl}$ and the $\mathrm{pH}$ was adjusted accordingly.

For overexpression in E.coli, overexpression plasmids were transformed into $E$. coli Rosetta (DE3) cells, which were grown for $\sim 16 \mathrm{~h}$ at $37^{\circ} \mathrm{C}$ in LB medium containing ampicillin $(100 \mu \mathrm{g} / \mathrm{ml})$ and chloramphenicol $(30 \mu \mathrm{g} / \mathrm{ml})$. Four litres of LB medium supplemented with ampicillin and chloramphenicol (100 $\mu \mathrm{g} / \mathrm{ml}$ and $30 \mu \mathrm{g} / \mathrm{ml}$, respectively) were inoculated with the pre-culture and grown at $37^{\circ} \mathrm{C}$ until an $\mathrm{OD}_{600}$ of $0.6-0.8$. The cultures were induced with isopropyl $\beta$-D-thiogalactopyranoside to a final concentration of $0.3 \mathrm{mM}$. Cells overexpressing biotinylated PfArll were further supplemented with Dbiotin to a final concentration of $50 \mu \mathrm{M}$. Growth was continued for $4 \mathrm{~h}$ at $37^{\circ} \mathrm{C}$ for $\mathrm{PfArlH}$, or for $16 \mathrm{~h}$ at $18^{\circ} \mathrm{C}$ for SaArlH, Strep-SaArll, and biotinylated PfArll. Cells were harvested by centrifugation and the pellets were either used immediately or stored at $20^{\circ} \mathrm{C}$. Cell pellets derived from cultures overexpressing SaArlH and PfArlH were suspended in $35 \mathrm{ml}$ of buffer A (50 mM HEPES pH 7.0, $150 \mathrm{mM}$ $\mathrm{NaCl}$ ) while cultures overexpressing Strep-SaArll and biotinylated PfArll were suspended in buffer B (50 mM Tris $\mathrm{pH} 8.0,150 \mathrm{mM} \mathrm{NaCl}$ ) plus $0.5 \%$ Triton $\mathrm{X}-100$ and one tablet of cOmplete ${ }^{\mathrm{TM}}$ Protease Inhibitor Cocktail Tablet (Roche).

\section{Protein purification}

When frozen, the pellets were thawed on ice. The suspensions in either Buffer A or Buffer B (for ArlH and Arll, respectively) were vortexed until homogeneity, a small amount of DNAse I was added and the cells were disrupted three times in a LM10 Microfluidizer $\AA$ device at 1500 bar. Cell debris was removed by centrifugation at $4500 \mathrm{~g}$ for 20 minutes. The supernatant was further centrifuged at $27200 \mathrm{~g}$ for 30 minutes. HIS-Select $®$ Nickel Affinity resin (Sigma) and Streptactin column material (IBA GmbH, Göttingen, Germany) were equilibrated with buffer A and $B$ respectively. The clarified lysate of cells overexpressing SaArlH, PfArlH or biotinylated PfArll were subsequently mixed with HIS-Select ${ }^{\circledR}$ Nickel Affinity resin (SIGMA) while lysate of cells overexpressing Strep-SaArll was mixed with Streptactin column material (IBA GmbH, Göttingen, Germany) and incubated at $4{ }^{\circ} \mathrm{C}$ with rotation for 1 hour, after which the mixture was poured into a gravity column. The flow-through was collected and 
bioRxiv preprint doi: https://doi.org/10.1101/2021.03.19.436134; this version posted March 19, 2021. The copyright holder for this preprint (which was not certified by peer review) is the author/funder, who has granted bioRxiv a license to display the preprint in perpetuity. It is made available under aCC-BY-NC 4.0 International license.

the column was washed with 10 column volumes (CV) of $50 \mathrm{mM}$ HEPES pH 7.0, $500 \mathrm{mM} \mathrm{NaCl}, 20 \mathrm{mM}$ imidazole and $20 \mathrm{CV}$ of $50 \mathrm{mM}$ HEPES pH 7.0, 150 $\mathrm{mM} \mathrm{NaCl}, 20 \mathrm{mM}$ imidazole for the HIS-Select $\AA$ Nickel Affinity resin and with $30 \mathrm{CV}$ of $50 \mathrm{mM}$ Tris $\mathrm{pH}$ 8.0 for the Streptactin column material. Proteins were eluted in 6 fractions of $1 \mathrm{ml}$. SaArlH was eluted in 50 $\mathrm{mM}$ MES pH 6.0, $150 \mathrm{mM} \mathrm{NaCl}, 200 \mathrm{mM}$ imidazole; PfArlH was eluted in $50 \mathrm{mM}$ HEPES pH 7.0, $150 \mathrm{mM}$ $\mathrm{NaCl}, 200 \mathrm{mM}$ imidazole; Strep-SaArll was eluted in $50 \mathrm{mM}$ HEPES pH 8.0, $150 \mathrm{mM} \mathrm{NaCl}, 2.5 \mathrm{mM}$ desthiobiotin; and biotinylated PfArll was eluted in 50 $\mathrm{mM}$ HEPES pH 8.0, $150 \mathrm{mM} \mathrm{NaCl}, 200 \mathrm{mM}$ imidazole. Imidazole was removed from purified $\mathrm{SaArlH}$ and PfArlH by overnight dialysis against their respective elution buffers without the imidazole and PfArll and biotinylated PfArll were further purified by size exclusion chromatography using a Superdex 200 Increase 10/300 GL column equilibrated with 50 mM HEPES pH 8.0, $150 \mathrm{mM} \mathrm{NaCl}$.

\section{In vitro phosphorylation assays}

ArlH was added to a concentration of $5 \mu \mathrm{M}$ in the presence of $0.01 \mathrm{mCi}$ (at least $17 \mathrm{nM}$ ) $\mathrm{y}^{-32}{ }^{32}$-ATP (or $\alpha-{ }^{32} \mathrm{P}-\mathrm{ATP}$ ) in a final volume of $100 \mu \mathrm{l}$ of $50 \mathrm{mM}$ MES $\mathrm{pH} 6.0,150 \mathrm{mM} \mathrm{NaCl}$ with $5 \mathrm{mM} \mathrm{MgCl} 2$ for SaArlH or, for $P$. furiosus proteins, buffer B with $5 \mathrm{mM} \mathrm{MgCl}_{2}$. Reaction mixtures were incubated for $S$. acidocaldarius proteins at $55^{\circ} \mathrm{C}$ and for $P$. furiosus proteins at $65^{\circ} \mathrm{C}$. At each time-point, $12 \mu \mathrm{l}$ were taken from each reaction mixture and mixed with an equal volume of $2 x$ concentrated Laemmli buffer. Samples were separated by SDS-PAGE and the radioactive signal was detected by autoradiography using the Typhoon FLA 9500 system.

\section{Motility assays}

The swimming assays were performed on semisolid $(0.15 \%)$ gelrite plates following the protocols described previously (10). Cells were grown until an $\mathrm{OD}_{600}$ of $0.4-0.5$. Samples of the cultures $(5 \mu \mathrm{l})$ were spotted on the gelrite plates, which were incubated for $4-5$ days in a humid chamber at $75^{\circ} \mathrm{C}$.

\section{Biolayer interferometry}

The Blitz $®$ system (Pall Life Sciences) was used to measure the interaction of SaArlH and SaArll. NiNTA biosensors (Pall Life Sciences) were prehydrated in the assay buffer $(20 \mathrm{mM}$ Tris $\mathrm{HCl} \mathrm{pH} \mathrm{8.0;}$ $150 \mathrm{mM} \mathrm{NaCl} ; 0.2 \%$ Tween-20) for 10 mins. Using the Blitz, biosensors were first equilibrated in the assay buffer for $30 \mathrm{~s}$, followed by incubation with 1 $\mu \mathrm{M}$ SaArlH in assay buffer for $30 \mathrm{~s}$ and equilibration in assay buffer for $600 \mathrm{~s}$ to establish a stable baseline. Then, the SaArlH-bound biosensors were dipped in assay buffer containing SaArll for $300 \mathrm{~s}$ to allow interaction. New NiNTA biosensors were used for each concentration of SaArll (261-4181 nM). Signals were corrected for a-specific binding of SaArll to the biosensors in the absence of SaArlH. Binding at $300 \mathrm{~s}$ was plotted against the SaArll concentration and fitted with the one site specific binding model $\left(B=B_{\max }{ }^{*}[\right.$ SaArll $] /\left(K_{D}+[\right.$ SaArll $\left.]\right)$, where $B=$ binding $[\mathrm{nm}] ; B_{\max }=$ binding at $300 \mathrm{~s}[\mathrm{~nm}]$; $\mathrm{K}_{\mathrm{D}}=$ equilibrium constant $[\mathrm{nM}] ;$ [SaArll $]=$ SaArll concentration) to determine the $\mathrm{K}_{\mathrm{D}}$.

\section{ATP binding assays}

Five micromolar ArlH in $150 \mu \mathrm{l} 50 \mathrm{mM}$ MES pH 6.0, $150 \mathrm{mM} \mathrm{NaCl}$ with $5 \mathrm{mM} \mathrm{MgCl} 2$ for $S$. acidocaldarius or buffer $B$ with $5 \mathrm{mM} \mathrm{MgCl}{ }_{2}$ for $P$. furiosus proteins was titrated with a MANT-ATP stock solution containing $5 \mu \mathrm{M}$ ArlH. Fluorescence intensity was recorded at excitation and emission wavelengths of 350 and $440 \mathrm{~nm}$, respectively, with slit widths of 2 $\mathrm{nm}$ in a temperature-controlled FluoroMax-4 spectrofluorometer (Horiba) at $20^{\circ} \mathrm{C}$. The fluorescent signal of MANT-ATP in the absence of protein was determined and subtracted and the fluorescence increase was plotted.

\section{ArlH labelling}

PfArlH ${ }^{\mathrm{S} 109 \mathrm{C}}$ was labelled with maleimide fluorescent dyes. ArlH was incubated with $10 \mathrm{mM}$ tris(2-carboxyethyl)phosphine in a volume of $200 \mu \mathrm{l}$ and a concentration of about $120 \mathrm{mM}$ for 20 minutes at room temperature. TCEP was removed by concentrating ArlH in PBS buffer (100 mM, pH 6.7) in centrifugal filters (Amicon ${ }^{\circledR}$ Ultra, cutoff $10 \mathrm{~K}$ ) to 150 $\mu \mathrm{l}$ and then washed, in the same centrifugal filter, for five times. The protein was then incubated with up to two fluorescent dyes (1.5-fold molar excess each) over night at $4^{\circ} \mathrm{C}$. Atto550 and Atto647N (ATTOTEC) were used. Afterwards, free dye was removed using a PD 25 MiniTrapTM (GE Healthcare) equilibrated in buffer $A$. The degree of labelling (DOL) was measured on a NanoDrop (Thermo ScientificTM). In case the DOL did not exceed $50 \%$, the protein was labelled once again for two hours at room temperature. PfArlIT411C was labelled in a manner similar to PfArlH, but in $50 \mathrm{mM}$ HEPES $\mathrm{pH}$ 8.0, $150 \mathrm{mM} \mathrm{NaCl}$ buffer.

\section{Single molecule TIRF experiments}

The experiments were carried out in a custombuilt prism type TIRF setup using two lasers at wavelengths $532 \mathrm{~nm}$ (green, Coherent ${ }^{\circledR}$ OBISTM LS) and $637 \mathrm{~nm}$ (red, Coherent $($ OBISTM LX) (68). The excitation beam is focused on a quartz prism and onto the flow chamber, which is passivated with a mixture of methoxy-silane-polyethylene glycol (5000 Dalton, Rapp Polymere) and methoxy-silane-PEGBiotin (3000 Dalton, Rapp Polymere) in an 80:3 ratio. Incubation with BSA solution for 30 minutes prior to measurement $(0.5 \mathrm{mg} / \mathrm{mL}$ in HEPES buffer, Carl Roth) further improved the passivation. To allow the biotinylated protein sample to bind to the surface, the chamber was further coated with NeutrAvidin (0.25 $\mathrm{mg} / \mathrm{mL}$, Thermo Fisher Scientific) and washed with HEPES buffer.

To test the oligomerisation of ArlH in presence of Arll, biotinylated Arll (10 nM) was flushed into the flow chamber and incubated for 10 minutes. Unbound sample was washed with buffer, before labelled ArlH (20 pM) was added. After an incubation time of another 10 minutes, excess protein was washed out with HEPES buffer.

For the autophosphorylation experiments, ArlH $(10 \mu \mathrm{M})$ was incubated with a hundredfold excess of ATP $(1 \mathrm{mM})$ for one hour at $65^{\circ} \mathrm{C}$ in HEPES buffer with $\mathrm{MgCl}_{2}(5 \mathrm{mM})$ prior to measurement. This 
procedure was also applied for the ATP-binding experiments, however, at room temperature.

To check the oligomer size of Arll, the procedure varied slightly: as the biotinylated Arll was labelled with fluorescent dye, only $20 \mathrm{pM}$ were flushed into the chamber to allow for single-molecule measurements.

The emitted fluorescence of the labelled sample is collected by an oil immersion objective (100x magnification, Nikon), separated according to wavelength and recorded by an EMCCD camera with 2x2 binning (iXon Ultra 897, Andor). The recorded movies are saved in the form of 16 bit TIFF stacks, which store the fluorescence intensities of the respective detection channels as successive frames (68).

The measurements were conducted using alternating laser excitation (ALEX) with an excitation time of $200 \mathrm{~ms}$ and a dark time of $50 \mathrm{~ms}$, whereby the two alternating wavelengths depended on the fluorescent dyes attached to the protein.

Data analysis of smTIRF experiments. Data selection was done in Igor Pro 6.37, using an inhouse script. It identifies the positions of single molecules by selecting the brightest spots in the respective detection channel, summing up five consecutive frames. Prior to our experiments, the green and red channel were aligned by image registration with fluorescent beads (TetraSpeck ${ }^{\mathrm{TM}}$ microspheres, $0.2 \mu \mathrm{m}$, Invitrogen $\left.{ }^{\mathrm{TM}}\right)$. Thus, fluorescence intensity traces in all excitation colors per single molecule could be obtained. From those, single molecule bleaching step traces were selected for analysis when having at least one bleaching step. To be recognised as such, the following three criteria must be met. First, a sudden drop in fluorescence intensity is not followed by another increase (blinking) but instead leads to a plateau. Second, in case of more than one bleaching step per trace, the plateaus have roughly the same height. Third, said plateaus are at least two frames (which equals $0.7 \mathrm{~s}$ ) long. Applying these criteria, the bleaching steps in each trace were determined and counted by eye by two independent researchers. This procedure was facilitated by using the fit generating function of AutoStepfinder (69). For each trace, fits displaying varying numbers of bleaching steps were created by adapting the parameters. By eye, the best fit was chosen. When measuring sample with two different fluorescent labels, one oligomer was characterized by two traces. Thus, the steps of both dyes were summed up to obtain the total number of bleaching steps. Afterwards, a histogram showing the absolute frequency per bleaching step was created, as well as another one showing the relative distribution. To correct for the degree of labelling (DOL), the latter was then fitted using a binomial distribution

$$
\left.=\left(\begin{array}{l}
n \\
b
\end{array}\right) * D O L^{b}(1-D O L)^{n-b}\right)
$$

with $n$ being the oligomer size and $b$ the observed bleaching steps. As zero bleaching steps cannot be observed in our experiments, the binomial distributions were truncated:

$$
\begin{gathered}
f_{o b s}(0)=0 \\
f_{o b s}(b)=\frac{f(b)}{1-f(0)}
\end{gathered}
$$

For a mixture of oligomer sizes ranging from monomers to hexamers, the distribution was given by a sum of binomials

$$
f_{n=[1,6] ; o b s}=\sum_{n=1}^{6} a_{n} * f_{n, o b s}
$$

with

$$
\sum_{n=1}^{6} a_{n}=1
$$

The values of the factors $a_{n}$ are obtained from the fitting procedure and correspond to the relative occurrence of each oligomer.

Every experiment was repeated at least once, however, the number of recorded traces per repetition varied between 173 and 995 traces. To create a joint bar chart in which each oligomer is weighted equally, the absolute frequencies per oligomer size and repetition were cumulated for all experiments. 95\% confidence intervals were given by the fitting procedure for each repetition. They were weighted as well according to the number of recorded traces to obtain uncertainties for the joined bar chart. To determine whether the means of two different conditions (e.g. oligomer size of phosphorylated $\mathrm{ArlH}$ compared to oligomer size of unphosphorylated $\mathrm{ArlH}$ ) differ significantly, a two-sample t-test was applied as our datasets are large enough (1906 traces for phosphorylated ArlH, 3671 traces for unphosphorylated ArlH and 2572 traces for ATPbinding, 423 for Arll) to fulfil the central limit theorem.

\section{Data availability}

All data described in the manuscript are presented in the main text, figures, and supporting information.

\section{Supporting information}

This article contains supporting information.

\section{Acknowledgments}


We thank Tomasz Neiner for initiating the measurements on autophosphorylation of $\mathrm{ArlH}$.

\section{Author contributions}

NM designed the experiments, performed and analysed experiments, and wrote the manuscript. LV and JS performed the experiments and analysed the data. RK and PC performed experiments. CvdD, TH and S.-V.A designed the experiments and wrote the manuscript. All authors read and contributed for the manuscript.

\section{Funding and additional information}

NM, LV, and JS were supported by the Collaborative Research Centre SFB1381 funded by the Deutsche Forschungsgemeinschaft (DFG, German Research Foundation) - Project-ID 403222702 - SFB 1381. NM was supported in part by the Excellence Initiative of the German Research Foundation (GSC-4, Spemann Graduate School) and in part by the Ministry for Science, Research and Arts of the State of Baden-Wuerttemberg.

\section{Conflict of interest}

The authors declare that they have no conflicts of interest with the contents of this article.

\section{References}

1. Beeby, M., Ferreira, J. L., Tripp, P., Albers, S.-V., and Mitchell, D. R. (2020) Propulsive nanomachines: the convergent evolution of archaella, flagella, and cilia. FEMS Microbiol. Rev. 10.1093/femsre/fuaa006

2. Pfeifer, F. (2015) Haloarchaea and the formation of gas vesicles. Life. 5, 385-402

3. Albers, S.-V., and Jarrell, K. F. (2015) The archaellum: how archaea swim. Front. Microbiol. 10.3389/fmicb.2015.00023

4. Albers, S.-V., and Jarrell, K. F. (2018) The archaellum: an update on the unique archaeal motility structure. Trends Microbiol. 10.1016/j.tim.2018.01.004

5. Jarrell, K. F., and Albers, S.-V. (2012) The archaellum: an old motility structure with a new name. Trends Microbiol. 20, 307-312

6. C. R. Peabody, Y. J. Chung, M.-R. Y, D. Vidal-Ingigliardi, A. P. Pugsley, and M. H. Saier Jr (2003) Type II protein secretion and its relationship to bacterial type IV pili and archaeal flagella. Microbiology. 149, 30513072

7. Streif, S., Staudinger, W. F., Marwan, W., and Oesterhelt, D. (2008) Flagellar rotation in the archaeon Halobacterium salinarum depends on ATP. J. Mol. Biol. 384, 1-8

8. $\quad$ Albers, S.-V., Szabó, Z., and Driessen, A. J. M. (2003) Archaeal homolog of bacterial Type IV prepilin signal peptidases with broad substrate specificity. J. Bacteriol. 185, 39183925
9. Tripepi, M., Imam, S., and Pohlschröder, M. (2010) Haloferax volcanii flagella are required for motility but are not involved in PibDdependent surface adhesion. J. Bacteriol. 192, 3093-3102

10. Lassak, K., Neiner, T., Ghosh, A., Klingl, A., Wirth, R., and Albers, S.-V. (2012) Molecular analysis of the crenarchaeal flagellum. Mol. Microbiol. 83, 110-124

11. Pohlschroder, M., Pfeiffer, F., Schulze, S. and Halim, M. F. A. (2018) Archaeal cell surface biogenesis. FEMS Microbiol. Rev. 42, 694-717

12. Thomas, N. A., Bardy, S. L., and Jarrell, K. F. (2001) The archaeal flagellum: a different kind of prokaryotic motility structure. FEMS Microbiol. Rev. 25, 147-174

13. Briegel, A., Ortega, D. R., Huang, A. N., Oikonomou, C. M., Gunsalus, R. P., and Jensen, G. J. (2015) Structural conservation of chemotaxis machinery across Archaea and Bacteria: structure of archaeal chemoreceptor arrays. Environ. Microbiol. Rep. 7, 414-419

14. Quax, T. E. F., Albers, S.-V., and Pfeiffer, F. (2018) Taxis in archaea. Emerg. Top. Life Sci. 2, 535-546

15. Schlesner, M., Miller, A., Streif, S., Staudinger, W. F., Müller, J., Scheffer, B., Siedler, F., and Oesterhelt, D. (2009) Identification of Archaea-specific chemotaxis proteins which interact with the flagellar apparatus. BMC Microbiol. 10.1186/14712180-9-56

16. Schlesner, M., Miller, A., Besir, H., Aivaliotis, M., Streif, J., Scheffer, B., Siedler, F., and Oesterhelt, D. (2012) The protein interaction network of a taxis signal transduction system in a halophilic archaeon. BMC Microbiol. 10.1186/1471-2180-12-272

17. Li, Z., Kinosita, Y., Rodriguez-Franco, M., Nußbaum, P., Braun, F., Delpech, F., Quax, T. E. F., and Albers, S.-V. (2019) Positioning of the Motility Machinery in Halophilic Archaea. mBio. 10, e00377-19

18. Li, Z., Rodriguez-Franco, M., Albers, S., and Quax, T. E. F. (2020) The switch complex ArICDE connects the chemotaxis system and the archaellum. Mol. Microbiol. 114, 468-479

19. Briegel, A., Oikonomou, C. M., Chang, Y., Kjær, A., Huang, A. N., Kim, K. W., Ghosal, D., Nguyen, H. H., Kenny, D., Ogorzalek Loo, R. R., Gunsalus, R. P., and Jensen, G. J. (2017) Morphology of the archaellar motor and associated cytoplasmic cone in Thermococcus kodakaraensis. EMBO Rep. 18, 1660-1670

20. Daum, B., Vonck, J., Bellack, A., Chaudhury, P., Reichelt, R., Albers, S.-V., Rachel, R., and Kühlbrandt, W. (2017) Structure and in situ organisation of the Pyrococcus furiosus archaellum machinery. eLife. 6, e27470

21. Kupper, J., Marwan, W., Typke, D., Grünberg, H., Uwer, U., Gluch, M., and Oesterhelt, D. (1994) The flagellar bundle of Halobacterium salinarium is inserted into a distinct polar cap structure. J. Bacteriol. 176, 5184-5187

22. Banerjee, A., Ghosh, A., Mills, D. J., Kahnt, J., Vonck, J., and Albers, S.-V. (2012) FlaX, A Unique Component of the Crenarchaeal 
Archaellum, Forms Oligomeric Ring-shaped Structures and Interacts with the Motor ATPase Flal. J. Biol. Chem. 287, 4332243330

23. Banerjee, A., Tsai, C.-L., Chaudhury, P., Tripp, P., Arvai, A. S., Ishida, J. P., Tainer, J. A., and Albers, S.-V. (2015) FlaF Is a $\beta$ Sandwich Protein that Anchors the Archaellum in the Archaeal Cell Envelope by Binding the S-Layer Protein. Structure. 23, 863-872

24. Tsai, C.-L., Tripp, P., Sivabalasarma, S., Zhang, C., Rodriguez-Franco, M., Wipfler, R. L., Chaudhury, P., Banerjee, A., Beeby, M., Whitaker, R. J., Tainer, J. A., and Albers, S.V. (2020) The structure of the periplasmic FlaG-FlaF complex and its essential role for archaellar swimming motility. Nat. Microbiol. 5, 216-225

25. Banerjee, A., Neiner, T., Tripp, P., and Albers, S.-V. (2013) Insights into subunit interactions in the Sulfolobus acidocaldarius archaellum cytoplasmic complex. FEBS J. 280, 61416149

26. Chaudhury, P., Neiner, T., D'Imprima, E., Banerjee, A., Reindl, S., Ghosh, A., Arvai, A. S., Mills, D. J., van der Does, C., Tainer, J. A., Vonck, J., and Albers, S.-V. (2015) The Nucleotide-Dependent Interaction of FlaH and Flal is Essential for Assembly and Function of the Archaellum Motor: FlaH and Flal interaction is nucleotide dependent. Mol. Microbiol. 99, 674-685

27. Reindl, S., Ghosh, A., Williams, G. J., Lassak, K., Neiner, T., Henche, A.-L., Albers, S.-V., and Tainer, J. A. (2013) Insights into Flal Functions in Archaeal Motor Assembly and Motility from Structures, Conformations, and Genetics. Mol. Cell. 49, 1069-1082

28. Chaban, B., Ng, S. Y. M., Kanbe, M., Saltzman, I., Nimmo, G., Aizawa, S.-I., and Jarrell, K. F. (2007) Systematic deletion analyses of the fla genes in the flagella operon identify several genes essential for proper assembly and function of flagella in the archaeon, Methanococcus maripaludis. Mol. Microbiol. 66, 596-609

29. Ghosh, A., and Albers, S. (2011) Assembly and function of the archaeal flagellum. Biochem. Soc. Trans. 39, 64-69

30. Patenge, N., Berendes, A., Engelhardt, H., Schuster, S. C., and Oesterhelt, D. (2001) The fla gene cluster is involved in the biogenesis of flagella in Halobacterium salinarum. Mol. Microbiol. 41, 653-663

31. Szabo, Z., Sani, M., Groeneveld, M., Zolghadr, B., Schelert, J., Albers, S.-V., Blum, P., Boekema, E. J., and Driessen, A. J. M. (2007) Flagellar motility and mtructure in the hyperthermoacidophilic archaeon Sulfolobus solfataricus. J. Bacteriol. 189, 4305-4309

32. Meshcheryakov, V. A., and Wolf, M. (2016) Crystal structure of the flagellar accessory protein FlaH of Methanocaldococcus jannaschii suggests a regulatory role in archaeal flagellum assembly. Protein Sci. 25, 1147-1155

33. Leipe, D. D., Aravind, L., Grishin, N. V., and Koonin, E. V. (2000) The bacterial replicative helicase DnaB evolved from a RecA duplication. Genome Res. 10, 5-16

34. Seraphim, T. V., and Houry, W. A. (2020) AAA+ proteins. Curr. Biol. 30, R251-R257

35. Johnson, C. H., Zhao, C., Xu, Y., and Mori, T. (2017) Timing the day: what makes bacterial clocks tick? Nat. Rev. Microbiol. 15, 232-242

36. Pattanayek, R., Wang, J., Mori, T., Xu, Y., Johnson, C. H., and Egli, M. (2004)

Visualizing a circadian clock protein: crystal structure of KaiC and functional insights. Mol. Cell. 15, 375-388

37. Hayashi, F., Itoh, N., Uzumaki, T., Iwase, R., Tsuchiya, Y., Yamakawa, H., Morishita, M., Onai, K., Itoh, S., and Ishiura, M. (2004) Roles of two ATPase-motif-containing domains in cyanobacterial circadian clock protein KaiC. J. Biol. Chem. 279, 5233152337

38. Hayashi, F., Iwase, R., Uzumaki, T., and Ishiura, M. (2006) Hexamerization by the Nterminal domain and intersubunit phosphorylation by the C-terminal domain of cyanobacterial circadian clock protein KaiC. Biochem. Biophys. Res. Commun. 348, 864872

39. Nishiwaki, T., Iwasaki, H., Ishiura, M., and Kondo, T. (2000) Nucleotide binding and autophosphorylation of the clock protein KaiC as a circadian timing process of cyanobacteria. Proc. Natl. Acad. Sci. U. S. A. 97, 495-499

40. Nishiwaki, T., Satomi, Y., Nakajima, M., Lee, C., Kiyohara, R., Kageyama, H., Kitayama, Y., Temamoto, M., Yamaguchi, A., Hijikata, A., Go, M., Iwasaki, H., Takao, T., and Kondo, T. (2004) Role of KaiC phosphorylation in the circadian clock system of Synechococcus elongatus PCC 7942. Proc. Natl. Acad. Sci. 101, 13927-13932

41. Nishiwaki, T., Satomi, Y., Kitayama, Y., Terauchi, K., Kiyohara, R., Takao, T., and Kondo, T. (2007) A sequential program of dual phosphorylation of KaiC as a basis for circadian rhythm in cyanobacteria. EMBO J. 26, 4029-4037

42. Rust, M. J., Markson, J. S., Lane, W. S., Fisher, D. S., and O'Shea, E. K. (2007) Ordered phosphorylation governs oscillation of a three-protein circadian clock. Science. 318, 809-812

43. Xu, Y., Mori, T., and Johnson, C. H. (2003) Cyanobacterial circadian clockwork: roles of KaiA, KaiB and the kaiBC promoter in regulating KaiC. EMBO J. 22, 2117-2126

44. Delalez, N. J., Wadhams, G. H., Rosser, G., Xue, Q., Brown, M. T., Dobbie, I. M., Berry, R. M., Leake, M. C., and Armitage, J. P. (2010) Signal-dependent turnover of the bacterial flagellar switch protein FliM. Proc. Natl. Acad. Sci. U. S. A. 107, 11347-11351

45. Engel, B. D., Ludington, W. B., and Marshall, W. F. (2009) Intraflagellar transport particle size scales inversely with flagellar length: revisiting the balance-point length control model. J. Cell Biol. 187, 81-89

46. Shu, D., Zhang, H., Jin, J., and Guo, P. (2007) Counting of six pRNAs of phi29 DNApackaging motor with customized single- 
molecule dual-view system. EMBO J. 26, 527-537

47. Ulbrich, M. H., and Isacoff, E. Y. (2007) Subunit counting in membrane-bound proteins. Nat. Methods. 4, 319-321

48. Zhang, H., and Guo, P. (2014) Single molecule photobleaching (SMPB) technology for counting of RNA, DNA, protein and other molecules in nanoparticles and biological complexes by TIRF instrumentation. Methods. 67, 169-176

49. Ghosh, A., Hartung, S., van der Does, C., Tainer, J. A., and Albers, S.-V. (2011) Archaeal flagellar ATPase motor shows ATPdependent hexameric assembly and activity stimulation by specific lipid binding. Biochem. J. 437, 43-52

50. Berry, J.-L., and Pelicic, V. (2015) Exceptionally widespread nanomachines composed of type IV pilins: the prokaryotic Swiss Army knives. FEMS Microbiol. Rev. 39, $1-21$

51. Story, R. M., Weber, I. T., and Steitz, T. A. (1992) The structure of the E. coli recA protein monomer and polymer. Nature. 355, 318-325

52. Egli, M., Mori, T., Pattanayek, R., Xu, Y., Qin, X., and Johnson, C. H. (2012)

Dephosphorylation of the core clock protein KaiC in the cyanobacterial KaiABC circadian oscillator proceeds via an ATP synthase mechanism. Biochemistry. 51, 1547-1558

53. Makarova, K. S., Aravind, L., Galperin, M. Y., Grishin, N. V., Tatusov, R. L., Wolf, Y. I., and Koonin, E. V. (1999) Comparative genomics of the Archaea (Euryarchaeota): evolution of conserved protein families, the stable core, and the variable shell. Genome Res. 9, 608628

54. Ishiura, M. (1998) Expression of a gene cluster kaiABC as a circadian feedback process in cyanobacteria. Science. $\mathbf{2 8 1}$, 1519-1523

55. Makarova, K. S., Galperin, M. Y., and Koonin, E. V. (2017) Proposed role for KaiC-like ATPases as major signal transduction hubs in archaea. mBio. 8, e01959-17

56. Loza-Correa, M., Sahr, T., Rolando, M., Daniels, C., Petit, P., Skarina, T., Gomez Valero, L., Dervins-Ravault, D., Honoré, N., Savchenko, A., and Buchrieser, C. (2014) The Legionella pneumophila kai operon is implicated in stress response and confers fitness in competitive environments. Environ. Microbiol. 16, 359-381

57. Liang, P.-J., Han, W.-Y., Huang, Q.-H., Li, Y.Z., Ni, J.-F., She, Q.-X., and Shen, Y.-L. (2013) Knockouts of RecA-like proteins RadC1 and RadC2 have distinct responses to DNA damage agents in Sulfolobus islandicus. J. Genet. Genomics. 40, 533-542

58. Ma, P., Mori, T., Zhao, C., Thiel, T., and Johnson, C. H. (2016) Evolution of KaiCdependent timekeepers: a proto-circadian timing mechanism confers adaptive fitness in the purple bacterium Rhodopseudomonas palustris. PLOS Genet. 12, e1005922

59. Schmelling, N. M., Lehmann, R., Chaudhury, P., Beck, C., Albers, S.-V., Axmann, I. M., and Wiegard, A. (2017) Minimal tool set for a prokaryotic circadian clock. BMC Evol. Biol. 10.1186/s12862-017-0999-7

60. Hayashi, F., Suzuki, H., Iwase, R., Uzumaki, T., Miyake, A., Shen, J.-R., Imada, K., Furukawa, Y., Yonekura, K., Namba, K., and Ishiura, M. (2003) ATP-induced hexameric ring structure of the cyanobacterial circadian clock protein KaiC. Genes Cells. 8, 287-296

61. Ye, J., Osborne, A. R., Groll, M., and Rapoport, T. A. (2004) RecA-like motor ATPases-lessons from structures. Biochim. Biophys. Acta BBA - Bioenerg. 1659, 1-18

62. Bagautdinov, B., and Kunishima, N. (2006) Purification, crystallization and preliminary crystallographic analysis of RecA superfamily ATPase PH0284 from Pyrococcus horikoshii OT3. Acta Crystallograph. Sect. F Struct. Biol. Cryst. Commun. 62, 412-414

63. Kang, H.-J., Kubota, K., Ming, H., Miyazono, K., and Tanokura, M. (2009) Crystal structure of KaiC-like protein PH0186 from hyperthermophilic archaea Pyrococcus horikoshii OT3. Proteins Struct. Funct. Bioinforma. 75, 1035-1039

64. Kang, H.-J., Kubota, K., Miyazono, K., and Tanokura, M. (2011) Expression, purification, crystallization and preliminary X-ray analysis of the KaiC-like protein $\mathrm{PH} 0187$ from the hyperthermophilic archaeon Pyrococcus horikoshii OT3. Acta Crystallograph. Sect. F Struct. Biol. Cryst. Commun. 67, 144-146

65. Chaudhury, P., van der Does, C., and Albers, S.-V. (2018) Characterization of the ATPase Flal of the motor complex of the Pyrococcus furiosus archaellum and its interactions between the ATP-binding protein FlaH. PeerJ. 6, e4984

66. Watson, J. F., and García-Nafría, J. (2019) In vivo DNA assembly using common laboratory bacteria: A re-emerging tool to simplify molecular cloning. J. Biol. Chem. 294, 1527115281

67. Brock, T. D., Brock, K. M., Belly, R. T., and Weiss, R. L. (1972) Sulfolobus: a new genus of sulfur-oxidizing bacteria living at low $\mathrm{pH}$ and high temperature. Arch. Für Mikrobiol. 84, 54-68

68. Götz, M., Wortmann, P., Schmid, S., and Hugel, T. (2018) Using three-color singlemolecule FRET to study the correlation of protein interactions. J. Vis. Exp. 10.3791/56896

69. Loeff, L. (2017) Microbial Warfare: Illuminating CRISPR adaptive immunity using single-molecule fluorescence. Ph.D. thesis, Delft University of Technology, 10.4233/UUID:08C08AEC-53F0-4419-BA9711FBB5A3DD49 